\title{
Negative Leadership: Promoting School Bullying and Ignoring the Mindfulness of Individual/Child
}

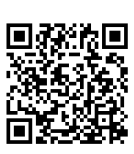

\author{
Mani Man Singh Rajbhandari ${ }^{1,2 *}$ \\ ${ }^{1}$ Professor/Researcher, CENTRUM Pontifical Catholic University of Peru, Peru \\ ${ }^{2}$ Executive Director/Senior Researcher, ORDT: Organization for Research Development and Training p. Ltd, Nepal
}

Submission: January 10, 2019; Published: February 14, 2019

*Corresponding author: Mani Man Singh Rajbhandari, Executive Director/Senior Researcher, ORDT, Organization for Research Development and Training Pvt Ltd, Professor/Researcher, Pontifical Catholic University, Peru, South America

\begin{abstract}
Leadership have multi-dimensional approaches so does the leader's and their leadership characteristics. These approaches and characteristics can be both negative and positive. However, negative leadership approaches are the cause and effects towards promoting school/organizational bullying within the organizational macro, meso and micro level. Although micro level bullying is often studied within the student's level, but peer bullying is also very likely causing the negativity environment. This peer bullying within the macro and meso level are the transformation through the negative leadership and leadership toxicity. Both these characteristics can have the immense impact within the organizational and home or social environs. Moreover, successful leaders' imitational impact of negative leadership is more likely to spread speedily than the less successful leaders' negative leadership.
\end{abstract}

This transformation of leadership both negative and toxicity leadership approaches can generate the leadership role model in the followership domain, which can further be transformed in their social arenas and social environs. Mindfulness at home and organization is essential, however, negative leadership and leadership toxicity can ignore the people's mindfulness creating unrest of mind and thus remain mindful to win over other and towards success of oneself.

Keywords: Mindfulness; Toxicity; Transformations; Classical Learning; Operant Learning; Cognitive and Social Learning; Leader; Leadership; Role Model; Personality; Bullying; Suppression; Oppression; Frustrations; Imitating Game; Behavior

\section{Introduction}

Leadership has been studied from different dimensions. This includes both the positive and the negative leadership approaches. Leadership approaches often is considered as a positive aspect to enrich followership domain. Rajbhandari \& Rajbhandari [1] states leadership is not complete and always needs maintenance especially with the maintenance of psychological, sociological and physiological (PSP) parameters in both the domains of leadership and followership. The leadership maintenance paradigm therefore enriches leaders and the followers in educational settings, thus eliminating the negative leadership and turning it into positive leadership through generating systemic and conducive PSP by having the mirror effects from leadership to followership and vice versa [2,3]. One of the dimensions of studying negative leadership is through understanding the school bullying. The question about exploring and understanding the negative leadership approaches of school bullying arises from who initiates and instigates for school bullying.

Although the question in relation to understanding this phenomenon is broad, it can be studied from multi-dimensional leadership approaches [2]. This dimension is closely knotted with the educational leadership, pedagogical leadership including teacher's leadership, and student's leadership approaches. Although these dimensions vary in contextual settings, these leadership settings are knotted tightly within leadership domain either producing positive or negative leadership within the school environment.

Who promotes the negative leadership is another dimension, this is necessary to understand? As negative leadership is tightly knotted in organizational bullying, this also have a negative followership approach. Organizational bullying or school bullying [4-6] does not only refer to student bullying the other student. This is also referred as to peer bullying and follower bullying. This peer bullying, workplace bullying, or organizational bullying can have multiple meaning from harassment of sexual abuse to abusive quarrelling, humiliations, argumentative instructions from senior peers and so forth $[6,7]$.

Organizational bullying generates a negative environment, thus producing the lack in followership's commitment including all the actors in schools. More often, school bullying is closely monitored within the student's parameters (Micro level). However, peer bullying (Meso Level) is nonetheless, the least factors most ignore to consider. In the other words, student bullying has 
become a natural practice in educational settings and does not account to contribute school effectiveness. However, peer bullying from the dimension of bullying from school leader to teachers and superior teacher (Macro Level) bullying their peer and colleagues are also imminent in organizational behaviour and contributes towards the growth of negative leadership. In all of these cases, mindfulness of followers is an utmost important factor which generates variations in contextual settings, thus producing a negative growth of school environment.

In educational settings, all these levels (Macro, Meso and Micro) [8] are interconnected and intertwined to each other. Variations in any of these levels can generate a vibe in the other level, producing a mirror effect through the cause and effect relations. However, amongst these levels, the effects of micro level are nominal but can cause a long-term slow effect. The variations in macro and meso level are strong and have fast reactions to produce mirror effects [9] between and amongst the leaders and peers. It is a leaders Skill, Ability, Competences and Intelligence (SACI) [10] to maintain organizational effectiveness by implying the Art and Science of Leadership towards maintenance of Leadership elasticity and leadership equilibrium [11].

Organizational bullying and school bullying are both produced from within and from outside environment. The within organizational bullying is a lack of positive leadership and this is either because of lame leadership or the negative leadership traits. Similarly, the outside bullying practices are more intense and have strong psychological, sociological and physiological (PSP) parameters connections to an individual traits and behavioral formations. The outside bullying PSP parameters are generated through the individual or child's surroundings and environments, especially, from the parents/guardians at home. This devolves the child unrest mind, which then is released at places during the absence of their parents. Moreover, the anger generated within the child unrest mind is released to others in the form of jealousy, criticism, competition, and wining over others by hurting in similar fashion regularly thus forming a pattern of negative leadership behavior. This is also accumulated through the achieved traits inherited from their parents/guardians, which the individual/child faces in regular social environs.

\section{Mindfulness at Home}

Tolerance at mind can blast if incase the individual/child is suffering from similar pattern of negative behavior at social environs. This can be brought about by different social interactive actors, such as, parents, spouses, guardian, neighbor and so forth Any sort of unlikely behavior which is being experienced in a regular and continuous basis in a similar pattern generates a mirror effect, causing an unrest mind to an individual. Experiencing the tolerance of unlikely pattern of negative behavior [12] frequently and continuously generates an anger mind. In few cases, the anger is released to the ones who is causing the disruptive behavior.

This settles down the unrest mind immediately, which can also have positive consequences in shaping the mindfulness of behavior towards others. However, many individual/children are weak and may not release their anger to the same person who is bullying them. Especially in the case of a child, they do not release their anger to their parents; however, their anger can be released to the same person as they reach a certain age. But in many cases, these unrest mind of the individual/child immensely activate at other places by releasing the same pattern of behavior that they are experiencing and thus forms a trait which quite often becomes their trademark.

Although the nature of releasing the unrest mind tensions may not be in the same fashion, it can be even bigger and devastating; however, this depends within the contextual environments. In some cases, few individuals/children may have been experiencing bullies at both places, which can be school/work place and at home or social environs. In such cases, form of releasing the tension of unrest mind could be hurting one self, which is a form of weaker personality traits [13-15]. Moreover, personality and cognition are similar which makes it difficult to make concrete distinctions [16] and understanding these two traits are even difficult and moreover, colliding to contradict these two as a similar trait can be devastating at times and situations, without proper understanding these two phenomena as a separate entity.

\section{Mindfulness at Workplace/School}

Workplace and school are the places where most individual and child spend their time by interacting and socializing themselves. What is so devastating is that when interactions and socializing comes to a halt that forms a situation of isolation and exclusion. In a situation of this kind of experiences, an individual/child releases their tensions, anger and stress at home amongst their children, parents, spouses, guardian and so forth. Contentious releasing of tension at home place can be a matter of transformation to bullying your own child/children. This can have a strong cause and effect relationship, which then a child/individual releases at others during the absence of their parents, guardians, spouse and so forth. In all these cases, remaining mindful of other and maintaining PSP parameters is an utmost important component that every one of us must consider seriously to prevent the transformation of bullying and negative leadership.

\section{Transformation of Mindfulness}

Social Transformation [17-19] of mindfulness [20-23] has become an essential component at home and workplace environments. Initiating the negative traits and behavior promotes and nurture bullies. This is often visible in shaping the negative behavior of individual/child reflecting the nature and the behavior of their parents and surroundings. Promoting negative behavior can sub-consciously be released towards others unknowingly, especially to a child. Although, parents, guardian, spouse, neighbor and so forth deny on promoting negative behavior, their small mistakes can become an error. Mistakes are to be rectified and must be corrected in parents, guardian, spouse and so forth and importantly child/children. This therefore promotes in generating mindfulness in an individual/child, which is then released in 
a similar pattern towards others. This releasing syndrome is a transformation of a learnt behavior of an individual/child of being mindful within themselves and towards others.

\section{Discussions and Conclusions}

Leadership can be both positive and negative. In most cases, the positive can have big positive impact towards followership domain. However, with negative leadership, it can put a big negative impact to the organizational climate [24]. Although various leadership styles are discussed within the leadership studies, among these leadership styles, autocracy leadership is one of the undesirable leadership style for the followers, however, this is not negative until it is generating task orientations behavior towards the betterment of organizations but not for oneself. While, autocracy leadership could be negative, if a leadership is doing best for oneself but not towards the organization and the followers. However, within the organization and people vs mindfulness, leadership can take a different turn, while win for the organization is little to be found and win for oneself is more likely and according to Sergiovanni [25] doing the best for oneself to win over others are even higher.

\section{Negative Leadership and Organizational Bullying}

Negative leadership [24] is an aspiring phenomenon towards generating organizational bullying. Negative leadership and organizational bullying may be totally a separable term; however, it is interconnected within a thin weave of thread, which may not be seen but can be felt.

Leadership can be transformed so does the bullying. Negative Leadership can have aspiring transformational speed through the leadership toxicity of behavioral approaches. These are transformed through the channel of macro, meso, micro and micro educational climates. Leadership toxicity can fast spread within the environment and can reach the followers domain and for some, it could be a way out for the imitation game. This negative imitation can have dramatic impact to the micro climate and so does to the meso level environment. Most adopt to survive in the organization and for some it could be the way of demonstrating the learnt behavior. This learning behavior is incorporated through the cognitive [26-29] and social learning [30,31], while operant learning $[32,33]$ plays the most minimum role. Although classical learning can have the immense impact to an individual learning, this causes the action of imitating toxicity leadership behavior.

This negative leadership promotes organizational bullying both in the meso and micro level. The trend of leadership toxicity and negativity approaches towards others is passed down to followers to ease the oppressed and suppressed psychological trauma and thought developing within an individual's mind. Moreover, remaining mindful within this toxicity of leadership approaches is difficult and may sometimes causes frustrations, which are further released at home with their spouse or children. This therefore is further transformed down to mold the attitudinal behavior of the children further generating their classical conditioning to imitate this leadership toxicity from their elders, which often are released from their parents.

Classical conditioning [34] is very strongly attached to ones learning behavior. Moreover, negative leadership imitations can agitate these learning to become more active within the social environments. However, operant learning is slow to develop and hence a child may not be sufficiently equipped. This is because; the cognitive paradigm of a child is also slow to develop.

The learnt behavior from the classical learning is strong because most individuals are attached to this environment, for example, when we go to some function, or in the speech, most people are day dreaming and at the end they clap to applauses, simply because other starts clapping. If you take a child to this speech function, it is definite that a child will also clap following the other. This is the reason why classical learning is very powerful.

\section{Leadership Role Model}

Leadership role model is essential, however, negative leadership and leadership toxicity imitation and implying in organizations or at home is not healthy to the environment. Toxicity leadership can have multiple paradigm. This could be released from our behavior, more often this is visible in an individual who have the type A Personality than in individual who have the Type B Personality. An action speaks louder than words, but in negative leadership and toxicity leadership both are louder. Both actions and words are crucial ingredient to promote organizational bullying, and this can be passed down through the channel of frustrations, anxiety, suppressions, oppressions, and so forth.

Leadership dominating styles and characteristic [35] suppresses followership domain and this is released further by the followers towards the down channel to release their anxiousness to others just to feel relief from the tensed situations. A dominating characteristic of a leader are transformed through the classical conditioning which may further be adopted by the learner as a negative leadership role model. This is possible, if a leader possessing this negative leadership quality and leadership toxicity is powerful, successful and demonstrative. For example, most often these phenomena can be linked and connected to the movie actors who always win despite all the odds [36].

In conclusion, negative leadership produces toxicity within the environment and outside. While leadership transformation is likely to be higher with those possessing success and fame, these leaders' characteristics of negative leadership are likely to be transformed quickly. In educational settings, we have competitions between schools, the best and the good to the worse. The best school's leader's negative leadership can have speedy transformation while compared to the worse school's leader's negative leadership. However, if we interchange the leaders from worse school to the best school, the result may be the same. Therefore, it is the social environment that generates the social inequity and hence the success wins over the odds and their 
characteristics are transformed easily and efficiently while those who are positive and are not successful.

\section{References}

1. Rajbhandari, MMS, Rajbhandari, S (2015) Leadership maintenance: Filling the gap for leadership competences. Educational Research and Reviews 10(21): 2777-2788.

2. Rajbhandari, MMS (2015) Critical Perspective on Situational Leadership Theory. Leadership Readiness for Flexibility and Mobility. The $4^{\text {th }}$ Dimensions on Situational Leadership Styles in Educational Settings. Europe.

3. Rajbhandari, MMS (2016) Why do educational leaders need maintenance? International Journal of Educational sciences 12(1): 1-6.

4. Darmawan (2010) Bullying in school: A study of Forms and Motives of Aggression in Two Secondary Schools in the city of Palu, Indonesia. Master's Thesis. University of Tromsø Norway. Indonesia.

5. VanDamme, E (2012) Identification and prevention of bullying in schools. Master's Thesis. Northern Michigan University. USA.

6. Eriksen, T, Nielsen, H, Simonsen (2012) The effects of bullying in elementary school. Economics Working Papers. Europe.

7. Quine, L (1999) Workplace bullying in NHS community trust: staff questionnaire Survey. BMJ 318: 228-232.

8. Rajbhandari, MMS (2011) Driving Leadership Style in Leading to Enhance Participation and Involvement in School. Europe.

9. Rajbhandari, MMS (2015) How Does Maintenance of Psycho-SocioPhysio Parameters Enrich Educational Leaders? Journal of Educational Thought/Revue de la Pensée Educative 48(3): 239-254.

10. Rajbhandari, MMS (2018) Theoractive Learning towards Academic Endeavour. Journal of Interdisciplinary Sciences 2(1): 1-7.

11. Rajbhandari, MMS (2017) Leadership Elasticity Enhancing StyleFlex for Leadership Equilibrium. International Journal of PsychoEducational Sciences 6(2): 76-88.

12. Michael JL Sullivan, Michael Conway (1989) Negative Affect Leads to Low-Effort Cognition: Attributional Processing for Observed Social Behavior. Social Cognition, 7(4): 315-337.

13. Mathews, G, Deary, IJ (1998) Personality Traits, Cambridge University Press, Cambridge, England.

14. Yazdanpanah M, Hadji Hosseinlou M (2017) The role of personality traits through habit and intention on determining future preferences of public transport use. Behavioural Sciences (Basel) 7: 1.

15. Weston, SJ, Hill PL, Jackson, JJ (2014) Personality traits predict the onset of disease. Social Psychological and Personality Science 72(6): 913-921.

16. Borghans Lex, Duckworth Angela L, Heckman James J, Weel Bas ter (2008) The Economics and Psychology of Personality and Motivation. Journal of Human Resources, Discussion, P. 3333.

17. Khondker, HH, Schuerkens, U (2014) Social transformation, development and globalization. Sociopedia.isa. UAE.
18. Webster C (2008) The Sociology of Transformation and the Transformation of Sociology in Southern Africa. Social Dynamics 24(2): 117-129.

19. Munck, R (1996) For a sociology of transformation. Transformation 29: 41-52.

20. Kabat-Zinn, J (2015) Mindfulness. Mindfulness 6(6): 1481-1483.

21. Davis DM, Hayes JA (2011) What are the benefits of mindfulness? A practice review of psychotherapy-related research. Psychotherapy 48: 198-208.

22. Thompson, C (2010) Everyday mindfulness. A guide to using mindfulness to improve your well-being and reduce stress and anxiety in your life. Europe.

23. Bandura A (1977) Social learning theory. Englewood Cliffs, NJ: Prentice-Hall, P. 247.

24. Oberlander, DM (2013) Negative Leadership. Master's Thesis. United States Army War College, USA.

25. Sergiovanni, TJ (1995) The politics of virtue: A new compact for leadership in schools. School Community Journal 5(2): 13-22.

26. McSparron, JI, Vanka, Smith, CC (2019) Cognitive learning theory for clinical teaching. Clinical Teacher's 15: 1-5.

27. Yilmaz, K (2011) The cognitive perspective on learning: its theoretical underpinnings and implications for classroom practices. The Clearing House: A Journal of Educational Strategies, Issues and Ideas 84(5): 204-212.

28. Chaffin, A, Harlow, S (2005) Cognitive learning applied to older adult learners and technology. Educational Gerontology 31(4): 301-329.

29. Grider G (1993) Foundations of cognitive theory: A concise review. Los Angeles, CA, USA: ERIC Clearinghouse for Community Colleges, USA.

30. Smith, M, Berge, Z (2009) Social learning theory in Second Life. The MERLOT Journal of Online Learning and Teaching 5(2): 439-445.

31. Grusec,JE (1994) Social learning theory and developmental psychology: The legacies of Robert R Sears and Albert Bandura. In RD Parke, PA Ornstein, JJ Rieser, C Zahn Waxler (Eds.), A century of developmental psychology (pp. 473-497). Washington, DC: American Psychological $\neg$ Association. UAS.

32. Wong, SW (2012) Operant learning theory. In Thyer, BA, Dulmus, CN, Sowers, KM (Eds.). Human behavior in the social environment: Theories for social work practice, 83-123. Wiley, New York.

33. Skinner, BF (1966) Operant behavior. In: Honig WK, editor. Operant Behavior: Areas of Research and Application. Appleton-Century-Crofts; New York, p. 12-32.

34. Pavlov, IP (1927) Conditioned Reflexes: An investigation of the physiological activity of the cerebral cortex. Ann Neurosci 17(3): 136141.

35. Rajbhandari, MMS (2006) Dominant leadership style in schools. Europe.

36. Hoel, H, Rayner, Cooper, CL (1999) Workplace bullying. In CL Cooper, IT Robertson (Eds.), International review of industrial and organizational psychology. New York, NY, US: John Wiley \& Sons Ltd 14: 195-230. 
This work is licensed under Creative Commons Attribution 4.0 License DOI: $10.19080 /$ ASM.2019.02.555600

\section{Your next submission with Juniper Publishers} will reach you the below assets

- Quality Editorial service

- Swift Peer Review

- Reprints availability

- E-prints Service

- Manuscript Podcast for convenient understanding

- Global attainment for your research

- Manuscript accessibility in different formats

( Pdf, E-pub, Full Text, Audio)

- Unceasing customer service

Track the below URL for one-step submission https://juniperpublishers.com/online-submission.php 